\title{
Nature of the Farm: Revisited
}

\author{
Matthew Elliott and Harvey S. James, Jr.
}

\begin{abstract}
We empirically test separation of ownership and control (SOC) and the interaction of SOC with farmer effort on farm success using data from the U.S. Department of Agriculture's Agricultural Resource Management Survey. We use a two-stage leastsquares approach with instrumental variables that proxy for participation constraints in binding incentive contracts. We find that the interaction has a significantly positive effect on success for grain farms and an insignificant effect for livestock farms. The results are consistent with hypotheses by Allen and Lueck (1998), but our model predicts that farms with SOC are likely to be more successful than farms without SOC despite exogenous uncertainty and agency costs.
\end{abstract}

Key Words: agency costs, contracts, farm organization, farm ownership, incentives, separated ownership and control, share contracts

An extensive literature documents the effects of different types of ownership on farmer incentives and farm success (e.g., Dasgupta, Knight, and Love 1999, Otsuka and Hayami 1988, Allen and Lueck 1998). An important issue explored in those studies is farm efficiency when decision agents do not fully bear the costs of their decisions, a form of ownership commonly referred to as separated ownership and control (SOC). A seminal work on this problem was conducted by Allen and Lueck (1998) (hereafter referred to simply as Allen and Lueck), who considered the tradeoffs between agency costs and the benefits of SOC through partnerships, corporations and vertical integration. They posited that, if specialization provides benefits, farms organized as partnerships and corporations would be more efficient than farms organized with a single agent having full ownership and control as long as the SOC partners could monitor and enforce agent effort efficiently. However, most types of agricultural production are heavily influenced by random shocks imposed by nature, making it costly to differentiate production deficiencies associated with lack of farmer effort from deficiencies associated with nature. Allen and Lueck argued that agency relationships and their associated costs are a central reason for why farms "will remain small and family farms will likely be with us a long time to come" (1998, p. 380). They noted that SOC farms were primarily either family farms or the result of offsetting lower

Matthew Elliott is assistant professor in the Department of Economics at South Dakota State University. Harvey S. James, Jr. is professor in the Department of Agricultural and Applied Economics at University of Missouri. Correspondence: Matthew Elliott - Department of Economics - South Dakota State University - 108 Scobey Hall, Box 0504 - Brookings, SD 57007 . Phone 605.688.4866 - Email matthew.elliott@sdstate.edu.

The views expressed are the authors' and do not necessarily represent the policies or views of any sponsoring agencies.

Agricultural and Resource Economics Review 46/1 (April 2017) 123-145

(C) The Author(s) 2017. This is an Open Access article, distributed under the terms of the Creative

Commons Attribution licence (http://creativecommons.org/licenses/by/4.0/), which permits unrestricted re-use, distribution, and reproduction in any medium, provided the original work is properly cited. 
costs to capital and specialization due to reductions in the randomness of nature.

We empirically test the effect of separating ownership and control and the interaction of separated control and operator effort on farm success using data for 2005 through 2010 from the U.S. Department of Agriculture's (USDA's) Agricultural Resource Management Survey (ARMS). Our approach follows the method used by Key and McBride (2008) to study the effects of adoption of production contracts on productivity of hog farms. However, we focus on all types of farms and compare farms that are exposed to greater uncertainty because of nature, such as grain farms, to farms that can reduce exogenous uncertainty using methods like climate-controlled confinement, such as livestock farms. We find that success can be significantly improved in grain farms when there is greater SOC and greater operator effort. ${ }^{1}$ However, we find no significant improvement for SOC livestock farms when there is greater SOC and operator effort. These results are consistent with Allen and Lueck's hypotheses. The greater exogenous uncertainty associated with grain production makes enforcing the operator's optimal effort more costly and can limit maximum farm performance in SOC farms. However, we find that SOC farms have superior farm performance despite differences in exogenous uncertainty and greater potential for suboptimal effort. Thus, greater specialization under SOC may allow for greater gains for some SOC farms that offset agency costs. Consequently, though we find evidence that the cost of agency may prevent the owner from fully enforcing optimal operator effort, we also find that the cost of agency does not completely prohibit agricultural operations from evolving to more SOC. Our results support the notion that agricultural operations will continue to evolve toward SOC despite agency costs associated with enforcing the desired level of effort in production when there is exogenous uncertainty.

Our study is important because there is evidence that farmers are increasingly adopting organizational structures characterized by greater degrees of SOC and vertical integration (e.g., Hoppe et al. 2001) (as we define and discuss in more detail later). An important question is whether farmers who separate ownership and control will then be at a competitive disadvantage relative to farmers who rely on traditional ownership and control structures, such as family owned and operated farms that are not vertically integrated. Gorton and Davidova (2004), for example, found no evidence that farms organized as corporations were inherently less efficient than family farms, and Key and McBride (2008) found that hog farmers who adopted production contracts were more productive than independent hog producers. Given these findings, Allen and Lueck's thesis of the limiting effect

\footnotetext{
1 Effort is defined as a unit of labor $(L)$ that produces a unit of output $(Q)$ given some units of capital $(K)$. We measure effort units as hours worked. Effective effort is defined as the ratio of one unit of labor $(L)$ that produces one unit of output $(Q)$ while holding capital $(K)$ constant.
} 
of agency costs has not been tested using contemporary data on farms' financial performance and changes in exogenous uncertainty. This study contributes to the literature by directly comparing financial performance indicators for farms in which ownership and control were more separate.

\section{Separation of Ownership and Control}

The literature on separating ownership from control has been built on work by Berle and Means (1932), Jensen and Meckling (1976), and Fama and Jensen (1983a, 1983b). Fama and Jensen (1983a, p. 9) defined SOC as separation of "management rights (initiation and implementation rights) and control rights of residual claimants (ratification and monitoring rights) to make decisions." They defined residual claimants as "agents who have rights to the difference between the stochastic inflows of resources and promised payments to other agents" (1983a, p. 3). Firms are distinguished by whether an agent who has rights to management decisions on behalf of the firm also possesses the full set of residual rights (combined ownership and control) or only possesses management rights and receives a wage and/or a partial right to residual claims. The studies focused on how organizations could most efficiently align the risk-bearing interests of residual claimants with managers' interests under SOC and any advantages SOC organizations offered. Advantages identified included sharing of risk, specialization in management and in bearing risk, ability to purchase specific assets, and the ability to invest according to the market value rule (Fama and Jensen 1983a). The primary economic disadvantage is that managers who have decision-making rights (i.e., agents) will not necessarily act in the interest of the risk-bearing owners (i.e., principals). Thus, the cost of agency is the cost incurred by the principals to measure and monitor the agent's performance, to ratify agent decisions, and from losses to residual claims from managerial opportunism (Fama and Jensen 1983a, 1983b, Jensen and Meckling 1976).

One line of study has explored features of share, cash, and wage contracts in agriculture production as a microcosm of SOC dilemmas (e.g., Stiglitz 1974). Early economic studies focused on the inefficiency of sharecropping due to agency costs (e.g., Marshall 1920). Subsequent research examined why sharecropping persisted in agricultural economies and co-existed with cash rent and wage contracts (e.g., Cheung 1969, Eswaran and Kotwal 1985, Stiglitz 1974, Allen and Lueck 1992). Allen and Lueck extended that research to explore discrete farm-organization choices (family farms, partnerships, and corporate farms). Their framework went beyond a study of the offsetting benefits of risk-sharing and agency costs in cash rent, sharecrop, wage, and owner/manager contract choices to address the existence and evolution of small family farms, farm partnerships, and corporate farms. In their framework, the agency cost arising from misalignment of the interests of the principal and agent could be offset by benefits from SOC associated with management specialization and lower capital costs. However, misalignment of 
agent incentives and an absence of enforcement or monitoring of agent effort would result in the agent reducing overall effort, which would lessen the specialization advantages from improving effective effort. This would be particularly prevalent when there is exogenous uncertainty. To ensure agents provide optimal effort, monitoring and enforcement of their effort and/or cooperative information-sharing is necessary to reduce asymmetric information regarding agent effort to the principal(s). Alternatively, asymmetric information could be reduced by reducing exogenous uncertainty. Here, agent effort is signaled to the principal efficiently by observing a signal correlated with agent effort such as the output. Reducing exogenous uncertainty is more likely in livestock operations where environmental uncertainty can be controlled through confined feeding operations (Mench et al. 2008) and efficient signaling can be obtained, and efficient cooperativeinformation sharing may be more prevalent in family owned and operated farms where there is greater trust and altruism (Scholes et al. 2007).

SOC in farm production occurs in three ways. In the first, control rights associated with residual claims are separated from management rights associated with factors of farm production such as land, machinery, and buildings. This type of SOC is often used in partnerships, corporations, and other types of multiple-owner farms in which the full or partial set of residual claims to factors of production is retained by the principals and the agent(s) have management decision rights to propose and initiate use of the factors of production. The second source of SOC involves the assignment of residual claims and management rights to the agricultural output. In most poultry-raising operations, for example, the residual claim to the output of grown birds is retained by the integrator or downstream buyer and a subset of management rights that affect the output is possessed by the poultry raiser (via a contract) for a period of time (e.g., Cunningham 2009). The third source of SOC is through changes in residual claims and management rights associated with the upstream and downstream supply and market assets. This form of SOC often occurs in cooperatives and other vertically integrated farm corporations. For example, most farmers who raise sugar beets have residual rights to sugar beet processing and marketing assets (e.g., brands) through various types of organization (i.e., cooperatives, limited liability corporations, etc.) but have separated the management rights and assigned them to specialized managers (e.g., Boland and Marsh 2006). The expected agency cost is economized by producer-members who reserve control through their right to ratify and monitor management decisions, either directly or through a representative board of directors. Regardless of the type of SOC, agency costs are assumed and are expected to increase with the degree of separation, thus requiring reservation of the right to monitor and ratify agent decisions to economize on the resulting agency costs.

In all three areas in which SOC can occur, we have historically observed an increasing level of SOC. First, factors of farm production have evolved to be more SOC. This is evident in the number of farm operations that have 
transitioned from sole proprietorships to partnerships and corporations. In 2007, 86.5 percent of U.S. farm firms were still organized as sole proprietorships, but during the preceding 40 years, the percentage of total agriculture sales attributed to sole proprietorships steadily declined, falling to approximately 50 percent (National Agricultural Statistics Service 2009), as shown in Figure 1. At the same time, a steadily growing percentage of total agricultural sales came from farms organized as partnerships and corporations. ${ }^{2}$ An analysis of data from the ARMS shows that farm managers who reported their organizations as sole proprietorships, partnerships, or corporations were associated with mean reported household percentage of ownership of their farms of 76 percent, 53 percent, and 58 percent respectively.

Second, some farms have evolved to be more SOC through adoption of production contracts, particularly in the poultry and hog sector. To identify this evolution, we must focus on changing decision rights possessed by the farm principal(s) and/or agent(s) (Hoppe et al. 2001). For example, the adoption of production contracts by U.S. farmers formalizes the transfer of a subset of management decision rights to a farm agent and defines the residual claimants' retained rights to monitor and ratify farm agent decisions in an increasingly integrated production process (MacDonald et al. 2004). This transfer of rights can occur in a proprietorship, partnership, or corporation but would represent a similar change to farm SOC.

Third, some farms have evolved to be more SOC as a result of increasing possession of direct or indirect residual claims to additional stages of the supply chain. For example, members of a federated farmer cooperative have increasingly possessed residual rights to branded consumer products managed by regional cooperatives. Farm managers/principals possess residual rights to regional cooperatives through their residual rights to local cooperatives. They often acquire residual rights to regional and local cooperative assets when they deliver output or otherwise patronize the local cooperatives. Expansion of farm decision-making rights through the growth and possession of residual claims to additional stages of the supply chain is typically initiated and implemented by local and regional cooperative managers and ratified by farm member/owners. The range of stages that are vertically integrated depends on the portfolio of assets maintained by the organization in which the farm agent(s) and/or principal(s) possess a significant proportion of residual claims and associated monitoring and ratification rights. In numerous cases in the United States and internationally,

2 SOC of factors of farm production can be used to facilitate generational farm transitions, reduce estate taxes, and distribute government farm program payments. However, SOC of family farms does not preclude the agency cost or persistent underperformance of resource use. Indeed, an agency cost is prevalent in cases that result in litigation. These cases have been extensively addressed in legal studies of optimal designs for family-farm governance contracts and methods by which courts can resolve multiple-owner family-farm conflicts (e.g., Bahls 1994). 


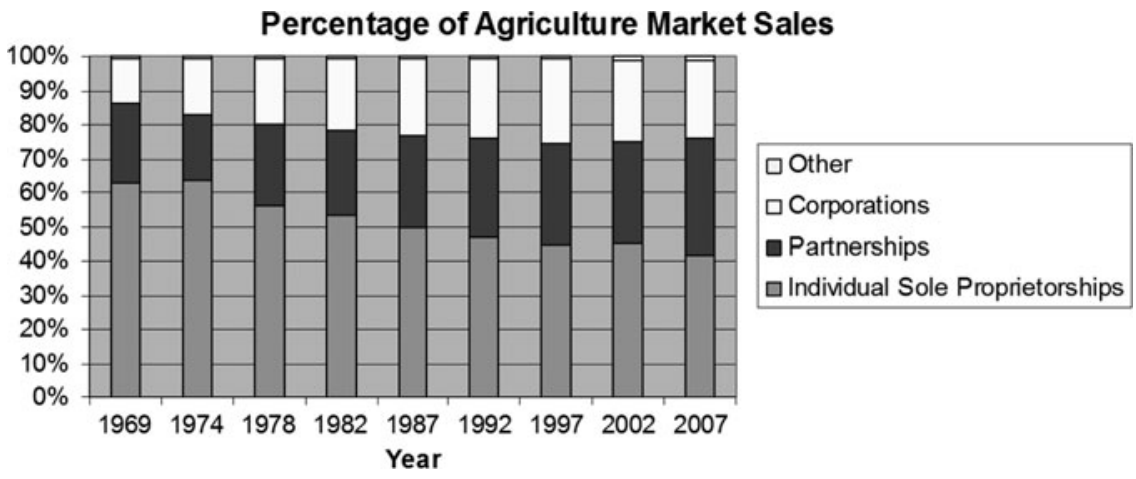

\section{Figure 1. Evolution of Farm Organization Share of Market Sales}

Source: National Agricultural Statistics Service, 2007 Agricultural Census (2009).

farm cooperative member/owners have gained the right to ratify and monitor many stages of production beyond planting/breeding, growing/husbandry, and harvesting, including fuel and fertilizer processing and marketing branded food products. The intent is to improve the performance of member farms by increasing gains to productivity and prices and/or reducing capital costs using collective governance of production stages beyond the farm compared to gains achievable in spot markets.

\section{Conceptual Framework and Hypotheses}

We are interested in understanding the relative efficiencies of SOC rights in agricultural production. Because prior research has suggested that crop and livestock operations have different efficiencies and levels of exogenous uncertainty (e.g., Latruffe et al. 2005), we estimate the effects of SOC for each type of operation. Our conceptual framework links ownership structure to farm success through specific indicators of efficiency: improvement in the amount of effort of the primary farm operator measured as effective labor effort and reductions in capital costs.

The underlying principal-agent framework involves a simple production function in which quantity of production $(Q)$ is dependent on a random factor $(\Theta)$ and is a function of capital $(K)$ and labor $(L)$ inputs and a technology represented as $Q=\Theta f(L, K)$. In SOC arrangements, the tenant or share owner acts as an agent of the land owner or other owners in the operation. The agent maximizes his or her own utility in terms of the amount of effort supplied and the owner's return from $Q$, plus wages or minus rents that are some fixed sum. The owner's objective function is to maximize the return on $Q$ and satisfy the agent-participation constraint (typically the prevailing wage 
rate). The agent's return $(Y)$ is determined by a share $(\delta)$ of $Q$ and/or a fixed component $(\beta)$ that is positive when the agent receives a wage and negative when the agent pays a cash rent $(Y=\delta Q+\beta)$. The agent's utility is a function of income and labor effort $(U=f(Y, L))$ in which expected utility is obtained by maximizing the return function $(Y=\delta Q+\beta)$ to obtain

$$
E U_{1} \delta \Theta f^{\prime}(L, K)+E U_{2}=0 .
$$

Here, we assume that the agent is risk-averse and that marginal disutility increases as labor effort and income increase. Moral hazard of the agent is created because $\Theta$ is random and results in a cost associated with contractually stipulating and enforcing the input of labor $(L)$. The amount of $L$ supplied is chosen by the agent, and the marginal productivity of that labor, $\left(f^{\prime}(L, K)\right)$, is not equated with the expected marginal substitution of utility between income and labor $\left(-E U_{2} / \Theta E U_{1}\right)$ when there is SOC $(\delta<1)$.

Allen and Lueck extended this basic model to explain the discrete choice of farm organization by offsetting the disadvantage of the agency cost associated with SOC with gains from specialization and lower capital costs associated with pooled resources. They parameterized labor specialization as a ratio by multiplying the number of farm laborers $\left(N_{s}\right)$ by the temporal length of the production stage $\left(L_{s}\right)$ and then dividing that value by the number of tasks in the stage $\left(T_{s}\right)$. They incorporated an exponential variable $\left(\alpha_{s}\right)$ that specified the degree of specialization gains that could be achieved where $\alpha_{s} \in[0,1)$. The specialization gain from each task in a given stage $\left(\left(a_{s}=N_{s} L_{s} / T_{s}\right)^{\alpha s}\right)$ was then multiplied by the sum of all task effort $\left(t_{s t n}\right)$ to derive the total effective effort in the stage $\left(e_{s t}=a_{s} t_{s t}\right)$ where $t_{s t}$ was the sum of all workers' task effort $\left(t_{s t}=\sum_{n=1}^{N} t_{s t n}\right)$. The effective effort is distinct from the level of effort under the sharecropping model because a productivity measure is added to each effort unit.

The Allen and Lueck model provides for offsetting effects for laborspecialization gains with agency costs from moral hazard when ownership and control are separated. This is done through optimal effort allocation to farm tasks given $N$ workers and the effective effort parameter $\left(e_{s t}\right)$. For example, a measure of effective labor effort $\left(e_{s t}=a_{s} t_{s t}\right)$ for five tasks in a single stage with length of one hour (i.e., $L_{s}=1$ ) when there are two partners will decrease at a slower rate than for a single owner as the degree of specialization gain approaches the maximum level. In the case of two partners and five tasks, the effective effort $\left(e_{s t}\right)$ of the partnership would equal $4 / 5$ or 0.8 when $\alpha_{s}=1$ and $2 / 5$ or 0.4 when $\alpha_{s}=0$ while a singleowner farm would be $1 / 5$ or 0.2 when $\alpha_{s}=1$ and 1 when $\alpha_{s}=0$. The specialization gains for partnership farms would be reduced further in the model due to the moral hazard effect, which is derived by maximizing gain to effort for each agent by allocating their optimal effort to $T$ farm tasks and to other labor market activities given the $N$ partners they have. Consequently, a single-owner farm allocates effort given $1 / T$ farm tasks. Alternatively, the 
first-order condition of the partnership model simplifies allocation of agent effort to the classic Marshallian share-crop equilibrium in which effort allocation for each task equals $1 / N_{s}$ when specialization gains are absent $\left(\alpha_{s}=0\right)$, and each partner's allocation of effort would resemble the single farmer's allocation of effort (i.e., 1/T) when specialization gains exist.

Allen and Lueck also added an improvement in the cost of capital as the number of partners grew with "factory corporate" farms having the minimum capital cost and "family farms" involving a single laborer having the maximum capital cost. Furthermore, they showed that vertical integration can benefit production processes that are temporally specific (as is common in agricultural operations) by reducing uncertainty across multiple stages of production. Therefore, vertical integration (and greater SOC) is more likely to occur when products, like agriculture products, are subject to a significant amount of uncertainty and the amount of task effort that optimizes their production across stages can be contractually stipulated.

An alternative framework for understanding the coexistence of different types of ownership of farm production and the effects of SOC on farm success and effort is through signaling and matching of capital and labor by the type of contracts offered and accepted (e.g., Hallagan 1978). In this framework, we expect that the relationships of the parameters of interest will be consistent with those of Allen and Lueck but for different reasons. In contrast to Allen and Lueck's asymmetric information assumption and offsetting gains from specialization and reduced capital costs, our signaling and matching framework assumes more-perfect information. Still, our expectations about the relationships in equilibrium are consistent. A high level of effort or endowment by agents is expected to be signaled by their bearing a larger share of the risk in full ownership and cash rent contracts; a low level of effort or endowment is signaled by their seeking wage and share contracts. Conversely, principals that have access to low-cost capital or the ability to monitor agents efficiently will offer wage and share contracts; principals for which the cost of monitoring agent effort is high will offer cash rent contracts to agents. The expected equilibrium is that principals that have a relatively efficient monitoring ability are matched with low-effort, unendowed agents in wage and share contracts while principals that have a relatively inefficient monitoring ability are matched with high-effort, endowed agents in cash rent contracts or other fixed payment instruments. The effect on farm success in this framework is a function of the combined entrepreneurial inputs provided by the principal and/or the agent.

Several studies have further incorporated signaling to identify optimal incentive schemes that could bind the agent's effort at the optimal level despite agent effort being hidden (e.g., Grossman and Hart 1983). An optimal binding incentive contract would result in the agent choosing effort, albeit hidden, that would maximize farm returns. The optimal returns could then be distributed fully or in part to the agent through the incentive contract and/or remain with the principal. With signaling, the problem presents cases in 
which the principal can use any observable signal of an agent's effort, such as output, to incentivize the desired level of effort when the principal has knowledge of the production function of labor and capital. The principal can then bind the agent's effort regardless of whether it can observe the agent's effort or reduce exogenous uncertainty. However, inducing a desired level of agent effort does not necessarily maximize benefits to the principal. An optimal incentive scheme must satisfy and bind the agent at the level of effort that provides the greatest probability of benefit relative to the lowest cost for the principal. Thus, one must identify the characteristics, benefits, and costs of the incentive schemes.

The principal-agent framework with signaling formalized by Grossman and Hart (1983) emphasizes the sensitivity of a binding, optimal incentive scheme to the costs associated with changes in the participation constraints. When the participation constraints vary due to exogenous factors and transaction costs, they can be used as instrumental, exogenous variables to predict changes in farm success via changes to the cost of incentive schemes that bind the agent's level of effort. Moreover, the incentive constraints can be related to changes in the benefit to the principal from greater agent effort and/or gains from specialization that are not offset by a loss of effort and thus increase the probability of farm success. In other words, areas in which non-farm wages are higher or the average farmer level of effort is lower may be correlated with regions in which specialized farm labor and vertical integration are more (or less) beneficial to the principal and/or agent.

By combining the frameworks of Allen and Lueck and of Hallagan (1978) with an understanding of the implications of changing the participation constraints on binding incentive schemes, we can econometrically analyze an equation with endogenous, jointly determined explanatory variables for farm success, SOC, and effort as

$$
\begin{aligned}
& \text { SOC }_{i}=a_{0}+a_{1} F S_{i}+a_{3} \text { Effort }_{i}+u_{1} \\
& F S_{i}=a_{0} / a_{1}+1 / a_{1} \text { SOC }_{i}-a_{3} \text { Effort }-u_{1} / a .
\end{aligned}
$$

To examine an equation of econometric interest and test the Allen and Lueck framework, we must analyze the second stage of a two-stage analysis in which only farm success $\left(F S_{i}\right)$ is endogenous:

$$
F S_{i}=\pi_{0}+\pi_{1} \widehat{\operatorname{SOC}}_{i}^{*}+\pi_{2} \widehat{S O C}_{i}^{*} \widehat{E f f o r t}_{i}+\pi_{3} \widehat{E f f o r t}_{i}+\pi_{4} X_{i}+\pi_{5} \text { Region }_{i}+u_{5}
$$

where $E\left(u_{5}=0\right)$ and $\operatorname{Cov}\left(u_{5}, Z_{i}\right)=0$. To do so, we replace the endogenous explanatory variables in the first equation with values predicted in the first stage using instrumental variables $\left(Z_{i}\right)$ (see equations 3,4 , and 5) that proxy changes in exogenous participation constraints that either affect the costs 
associated with binding incentive contracts or are correlated with benefits from specialized/endowed farm labor. The predicted degree of SOC $\left(\widehat{S O C}_{i}\right)$ and level of effort of the primary farm operator $\left(\widehat{E f f o r}_{i}\right)$ are then used in the equation of interest to determine the relationship between farm success and level of effort and SOC on farm success. The interaction of predicted effort and SOC is expected to be particularly important to farm success. Because we expect to see specialization or a high level of endowment when effort and SOC are combined, effort that exceeds the mean level under SOC and an absence of agency costs from agent or managerial opportunism should improve farm success. We also include control variables $\left(X_{i}\right.$ and Region $\left._{i}\right)$ in the first and second stages of the analysis.

$$
\widehat{\text { Effort }}_{i}=\beta_{0}+\beta_{1} Z_{i}+\beta_{2} X_{i}+\beta_{3} \text { Region }_{i} .
$$

$$
\widehat{S O C}_{i}=\alpha_{0}+\alpha_{1} Z_{i}+\alpha_{2} X_{i}+\alpha_{3} \text { Region }_{i}
$$

$$
\widehat{\operatorname{SOC}}_{i}^{*} \widehat{\text { Effort }}_{i}=\eta_{0}+\eta_{1} Z_{i}+\eta_{2} X_{i}+\eta_{3} \text { Region }_{i}
$$

Given this framework and our econometric equations, we empirically test three hypotheses.

Hypothesis 1: Effort has a unique positive effect on farm success $\left(\pi_{3}>0\right)$.

We expect a greater level of effort of the farmer or operator to have a positive effect on farm success when controlling for SOC. That is, if we continue with the preceding example for the specialization parameter by Allen and Lueck and assume that the total stage length is one hour and that the degree of specialization that can be achieved is great (i.e., $\alpha_{s}=1$ ), a partnership farm involving two laborers and five tasks would have an effective effort scaler of 0.8 while a single farmer-laborer would have an effective effort scaler of 0.2 . Both farms would allocate the same effort to the five tasks, in this case 0.2 hours. Consequently, for the single farmer to have total effective effort equivalent to the partnership farm, the single farmer would need to allocate four times the task effort. If the degree of specialization for the three tasks is low (i.e., $\alpha_{s}=0$ ), however, the partnership farm would require more than twice as much task effort from the partners to have an equivalent total effective labor effort as the single farmer. ${ }^{3}$ If labor effort is not increased

\footnotetext{
3 If the partnership $e_{s t}$ was 0.4 and 0.1 hour was allocated to the five tasks by each partner, then,
} given the moral hazard effect $1 / N$, the total effective effort for all tasks would be 0.4 between the 
because of agency costs from agent opportunism or inability to allocate additional task effort given seasonal determinations of stage length, then farm success will decrease.

\section{Hypothesis 2: Separated ownership and control has no unique effect on farm success $\left(\pi_{1}=0\right)$.}

Combined ownership and control is expected to improve farm success by providing an incentive for greater farmer effort, and SOC and vertical integration are expected to improve farm success by reducing the cost of capital and gains from specialization. Thus, if we include the cost of capital, specialization gains, and effort in the model, we do not expect SOC to be significant in explaining farm success because it would provide redundant information on performance changes to the farm operation for which we already controlled.

Hypothesis 3: The interaction of SOC and standardized effort has a unique positive effect on farm success $\left(\pi_{2}>0\right)$ in the presence of uncertainty in production and specialization gains.

The interaction of effort and SOC is expected to have a significant, positive effect on farm success when there is sufficient exogenous uncertainty. We expect that agents will reduce their level of effort in SOC when there is exogenous uncertainty because they do not bear the cost of that reduction, and it is more difficult to design an optimal, binding incentive contract. A positive, significant interaction of effort and SOC indicates that there is an offsetting gain to the decrease in agent effort (through gains from specialization). ${ }^{4}$ Though, when there is less exogenous uncertainty, the interaction will be less significant because optimal effort can be bound contractually, and the unique effects of effort and SOC will have greater explanatory power of farm success.

\footnotetext{
two partners. This is in comparison to a single farmer whose $e_{s t}$ was 1 and who allocated 0.2 effort to each task for a total effective effort of 1 for all the tasks.

4 When the SOC score is higher/positive (lower/negative) than average and is multiplied by a positive standardized level of farmer effort (effort exceeded the mean), a positive (negative) coefficient $\left(\pi_{2}\right)$ points to a positive (negative) effect on farm success that adds to (offsets) the unique effect of effort and SOC on farm success in the equation. Essentially, the interaction term provides a proxy that corrects the unique effect of effort on farm success by including the theoretical variable for effective effort. This allows us to explore whether greater theoretical effective effort is significant in explaining farm success or whether farm success is largely explained by the unique effects of effort and SOC.
} 


\section{Methods and Data}

We test the relative efficiencies of various forms of SOC using data from ARMS for 2005 through 2010. ARMS is a multi-phase, multi-level nationwide survey of agricultural producers that collects information on the financial performance, farm organization characteristics, management techniques, use of contracts, and demographic characteristics. Each year, approximately 30,000 producers are randomly targeted to respond to the survey using a list or area frame, and a subset of producers provide commodity-specific (e.g., corn producers) information about their farm management practices and use of resources at the field level (Phase II). The full sample across all commodities provides reference information on their farm financials, household income, and farm and household characteristics (Phase III). The Economic Research Service (ERS) provides additional data related to the environment in which the farms operate, including prevailing wage rates, the population, and the county's economic dependence on farming.

The ARMS data set is superior to the bi-regional data set used by Allen and Lueck for empirically testing the hypotheses because it provides multiple variables related to farms' structure, performance, incentives, and hours worked and captures changes in exogenous uncertainty for large regions, scopes of production, and time frames. The ARMS data allow us to test the theoretical constructs of interest relatively directly while adequately controlling for endogeneity using exogenous instrumental variables. Thus, the data set is well suited for examining our hypotheses and will provide empirical evidence that can shed light on longstanding questions regarding farmer incentives and effort and the efficiency of farms in the context of exogenous uncertainty.

We test the relationships between farm success and effort and SOC with a two-stage least-squares (2SLS) approach using the Syslin Procedure in SAS 9.3. We also examine the validity of the instrumental variables in our model using the Basmann (1960) over-identification test to determine if there is correlation between the error term and the instrumental variables that would bias the coefficients. We also examine the first-stage F-tests for the suitability of our instruments in predicting the endogenous variables.

Prior to applying the 2SLS procedure, we had to score the theoretical variables using the factor procedure and the principal component analysis method. We use the principal component score because multiple manifest variables in the data set reveal the theoretical constructs identified in our conceptual framework. The factor procedure reduces those manifest variables to a single theoretical construct described by optimally weighting each manifest variable to maximize the variance explained by the theoretical construct.

The first principal component variable measured is SOC (SOC). The degree to which ownership and control is separated increases (i) in the number of owners who have residual claims but do not manage the business and (ii) in the 
presence of hired managers or employees who do not own all of the factors of production or the production and who work under a wage, piece-rate, or partial-share incentive system. Given the theoretical variable of interest and the manifest variables available in the data, we score the SOC principal component using three standardized scores: the ratio of wage expense to total expense (ZRatio_Hired_Labor), the percent share of ownership held by the operator's household (ZOwnershare) with the operator defined as the primary manager of the farm, and the type of farm organization, which indicates whether there is a principal-agent relationship (ZFarm_Org). Principal operators in the ARMS survey reported the type of organization for their farms as sole proprietorship, partnership, corporation, or trust, and we scored sole proprietorships as 0 , trusts and partnerships as 1 , and corporations as 2 .

We expect the $S O C$ component score to have a positive relationship with the variables for the ratio of wages to expenses and type of farm organization and a negative relationship with the primary operator's ownership share. The single SOC component we extracted had an eigenvalue of 1.424 and explained 47.48 percent of the variance of the three manifest variables. The eigenvalues for the second and third components of the analysis did not exceed 1.0, the commonly accepted threshold for extracting additional components to explain the variance (Kaiser 1960). The optimal weights of the variables were derived by maximizing the variance explained using an eigen equation. The components were identified in sequential order by the degree of variance explained and were orthogonal to the previously extracted component(s). The SOC component score was calculated as

$$
\begin{aligned}
\text { SOC }= & 0.561(\text { ZFarm_Org })-0.334(\text { ZOwnershare }) \\
& +0.525(\text { ZRatio_Hired_labor }) .
\end{aligned}
$$

In this scoring, we omitted variables in the data set that indicated the presence of vertical integration, such as production contracting and cooperative investment. We did this for simplicity and because such variables are significantly correlated with the SOC score we obtained. ${ }^{5}$

The second principal component variable measured is farm success. Allen and Lueck did not explain farm success; instead, they explained types of farms that persisted using the assumption of profit maximization. We define farm success in the context of the principal-agent framework as provision of the greatest return (in dollars) that can be divided between the principal(s) and agent.

\footnotetext{
5 The Pearson two-tailed correlation coefficients between the calculated SOC score (SOC) and scores for farms that used livestock production contracts (0.039), farms that used crop production contracts (0.089), and farms that had cooperative investments (0.064) are all significant at the 1 percent level.
} 
Based on existing economic studies of farm success (e.g., Mishra, El Osta, and Johnson 1999), we used two common financial measurements that indicate farm success and would reflect returns to both the principal and agent: return to labor and management $(Z R L M)$ and return to capital $(Z R C)$. Return to labor and management is the dollar value return (in thousand dollars) that can be distributed to labor, capital, and management after expenses. It is calculated by summing net farm income, hired labor expense, interest on debt, and rent (share or cash) and then subtracting 4 percent of the total market value of land, buildings, and equipment (rented and owned) as an arbitrary opportunity cost to capital. Return to capital is calculated as net farm income minus the charge for unpaid operator and management labor and unpaid nonoperator labor plus interest expense and rent divided by market value of land, buildings, and equipment (owned or rented). The eigenvalue of the farm success component was 1.459 and explained 72.9 percent of the variance of the two manifest variables. We calculated the principal component score for farm success using the method used for the SOC variable:

$$
F S=0.585(Z R C)+0.585(Z R L M) .
$$

The four instrumental variables used in the 2SLS analysis met three criteria; they were (i) expected to be correlated with the cost-of-participation constraints for binding agent effort and benefits that could be gained by the principal, (ii) were expected to be uncorrelated with the error term in the second stage of the model, and (iii) were available or could be derived using the ARMS data set. DOPHRS represents mean annual hours worked per farm by principals and agents in each agricultural reporting district. ERS_FM is an indicator variable that denotes whether the county in which the farm was located was economically dependent on farming as defined by ERS. A classification variable, $E R S_{-} B L 93$, indicates the degree to which the county in which the farm was located was rural or metropolitan on a scale of 1 through 9 where 1 is mostly rural and 9 is mostly urban, and Dreal_interest represents the mean interest rate of real estate loans for the agricultural reporting district. The notion behind using these instrumental variables is that the desirability of alternative effort devoted to something other than farming for all farm producers decreases as the rural nature of the county increases. Moreover, as fixed capital costs increase and alternative uses for capital besides farming become available (e.g., development), it could be less desirable and perhaps less beneficial to devote capital to SOC farm production.

Our jointly determined endogenous model uses the operators' annual hours worked on the farm as the measure of effort (the SOC principal component) and the principal component score for farm success as the dependent variable. In the first and second stages of the model, we include a proxy for the cost of capital (ZExp_Cap) and a square term of that variable (ZExp_Cap ${ }^{2}$ ). Following Allen and Lueck, we use a standardized ratio of farm expense to 


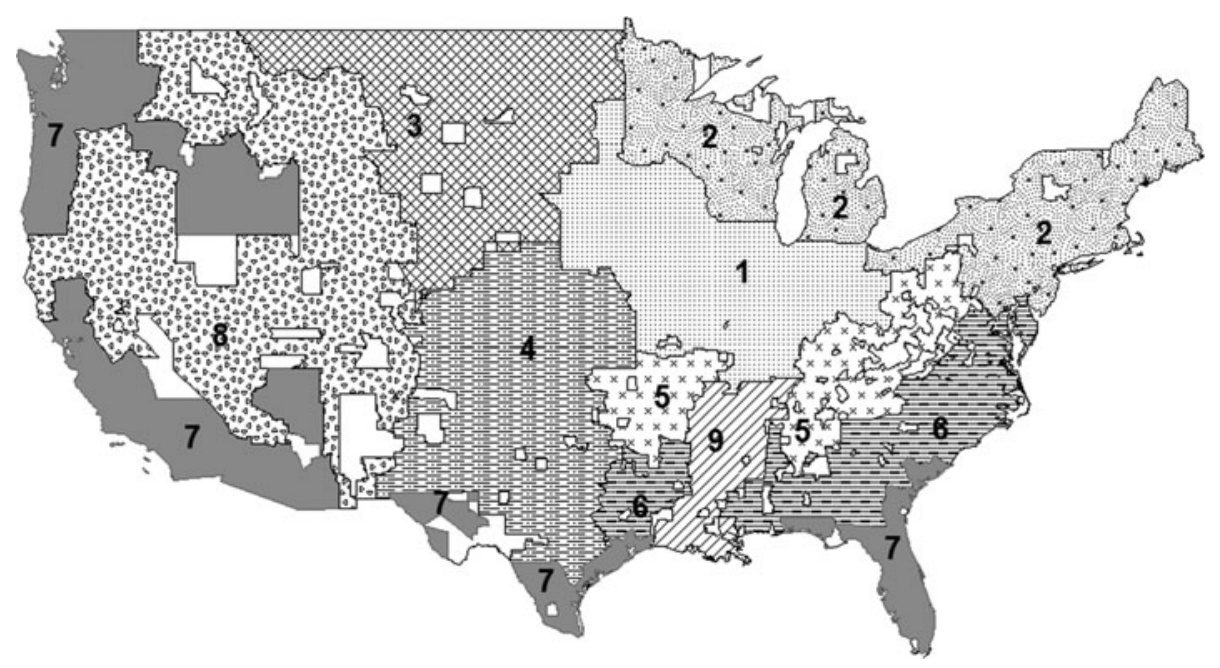

Figure 2. USDA ERS Resource Regions

the reported market value of capital as a proxy for the cost of capital. ${ }^{6}$ There is an optimal ratio of mean expense to capital at which the measure of the farm's success is greatest, and farm success remains positive moving away from that optimal point in either direction until the marginal cost exceeds the marginal revenue or the marginal revenue exceeds the marginal cost. At those points, farm success becomes negative. We also include several control variables: operator age, dummy variables for the year of the ARMS survey (excluding 2005), and spatial dummy variables for the ERS resource region (shown in Figure 2) in which the farm is located (we do not include a dummy variable for region 9, the Mississippi Portal region).

We identify each observation in the data set as primarily either a grain farm or a livestock operation to analyze the effect of a difference in exogenous uncertainty hypothesized in the theory and analyze those sets of observations separately. The exogenous uncertainty faced by the individual farms in each category might not be homogenous, but we posit that this separation of the data is sufficient for our purposes since grain producers are less able to mitigate uncertainty than livestock producers.

\footnotetext{
6 In our model, the farm expenses include operating expenses and depreciation and interest. The market value of capital includes the reported value of the land, machinery, and buildings owned and rented by the farm. The ratio is expected to be large when capital is costly to acquire and when capital is not efficiently used, which we identify as operations that exhibit excess capital capacity that depreciates or results in repair expenses that are inefficiently spread over other units of production.
} 
Table 1. Second-stage Livestock Parameter Estimates with Farm Success as the Dependent Variable

\begin{tabular}{|c|c|c|c|}
\hline Variable & Parameter & Standard Error & t-Value \\
\hline Intercept** & -0.267 & 0.131 & -2.05 \\
\hline SOC & 0.215 & 0.128 & 1.68 \\
\hline SOC_ZEffort & 0.012 & 0.153 & 0.08 \\
\hline Effort ${ }^{* * *}$ & 0.0001 & 0.000 & 3.83 \\
\hline OP_AGE & -0.001 & 0.001 & -1.89 \\
\hline ZExp_Cap*** & 0.243 & 0.018 & 13.78 \\
\hline ZExp_Cap ${ }^{2 * * *}$ & -0.001 & 0.000 & -13.08 \\
\hline Y2010 & 0.106 & 0.075 & 1.41 \\
\hline Y2009 & 0.076 & 0.062 & 1.22 \\
\hline Y2008 & 0.096 & 0.065 & 1.47 \\
\hline Y2007*** & 0.165 & 0.063 & 2.63 \\
\hline Y2006 & 0.041 & 0.026 & 1.6 \\
\hline ERS1** & -0.010 & 0.035 & -2.78 \\
\hline ERS2*** & -0.252 & 0.036 & -7.1 \\
\hline ERS3 & -0.150 & 0.045 & -3.34 \\
\hline ERS4 & -0.046 & 0.036 & -1.29 \\
\hline ERS5** & -0.092 & 0.037 & -2.53 \\
\hline ERS6 & -0.064 & 0.039 & -1.66 \\
\hline ERS7 & -0.050 & 0.045 & -1.12 \\
\hline ERS8*** & -0.169 & 0.045 & -3.74 \\
\hline
\end{tabular}

Notes: Testing for over-identifying restrictions (d.f. $=1$ ) results in $\operatorname{Pr}>\mathrm{F}$ or 0.9929 . Model d.f. $=19$. $\mathrm{F}$-value $=45.57$ with $\operatorname{Pr}>\mathrm{F}<0.0001$. R-square $=0.014$. ${ }^{* *} \mathrm{P}<0.05 ;{ }^{* * *} \mathrm{P}<0.01$.

\section{Results}

We report the results of the second stage of our analysis for the 2SLS models and of Basmann (1960) over-identification tests in Tables 1 (for livestock operations) and 2 (for grain operations). Results of the first stage of the analysis are reported in the appendix. The results indicate that the selected instrumental variables are not correlated with the error terms in the second stage (F-tests of 0.03 and 0.00 ). Thus, we do not expect the instrumental variables to bias the coefficients from our hypothesis tests. Furthermore, our review of the instrumental variables in the first stage (Effort, SOC, and SOC_ZEffort) indicates an acceptable degree of independence and joint explanatory power. Given the results from the first stage, we determined that our predicted variables in the second stage were adequate to test our hypotheses. 
Table 2. Second-stage Grain Parameter Estimates with Farm Success as the Dependent Variable

\begin{tabular}{|c|c|c|c|}
\hline Variable & Parameter & Standard Error & t-Value \\
\hline Intercept ${ }^{* * *}$ & -0.413 & 0.070 & -5.94 \\
\hline SOC & 0.009 & 0.060 & 0.15 \\
\hline SOC_ZEffort** & 0.494 & 0.192 & 2.57 \\
\hline Effort*** & 0.0001 & 0.000 & 9.83 \\
\hline OP_AGE & 0.0004 & 0.000 & 1.00 \\
\hline ZExp_Cap*** & 3.972 & 0.182 & 21.88 \\
\hline ZExp_Cap ${ }^{2 * * *}$ & -0.072 & 0.003 & -21.78 \\
\hline Y2010 & 0.040 & 0.036 & 1.11 \\
\hline Y2009 & 0.016 & 0.032 & 0.5 \\
\hline Y2008 & 0.036 & 0.029 & 1.24 \\
\hline Y2007*** & 0.080 & 0.026 & 3.04 \\
\hline Y2006*** & 0.060 & 0.016 & 3.72 \\
\hline ERS1 & 0.011 & 0.020 & 0.53 \\
\hline $\mathrm{ERS} 2 * * *$ & -0.123 & 0.035 & -3.49 \\
\hline ERS3 & 0.006 & 0.026 & 0.23 \\
\hline ERS4 & 0.026 & 0.024 & 1.06 \\
\hline ERS5** & -0.114 & 0.047 & -2.43 \\
\hline ERS6*** & -0.095 & 0.022 & -4.33 \\
\hline ERS7** & 0.130 & 0.065 & 2.01 \\
\hline ERS8 & -0.003 & 0.034 & -0.09 \\
\hline
\end{tabular}

Notes: Testing for over-identifying restrictions (d.f. $=1$ ) results in $\operatorname{Pr}>\mathrm{F}$ or 0.8534 . Model d.f. $=19$. $\mathrm{F}$ value $=263.61$ with $\mathrm{Pr}>\mathrm{F}<0.0001$. R-square $=0.086 .{ }^{* *} \mathrm{P}<0.05 ;{ }^{* * *} \mathrm{P}<0.01$.

We find that primary operator effort is significantly positive for farm success for grain and livestock operations. The coefficient of 0.0001 (Table 1, livestock) is statistically significant and consistent with hypothesis 1 . This result suggests that an increase (decrease) of one hour of operator effort will improve (weaken) the farm success score by 0.0001 , ceteris paribus.

Also, as expected, we find that SOC is not significant in explaining farm success when we control for the cost of capital. Therefore, the farm success score is unlikely to increase or decrease in response to changes in the farm structure alone and may be a redundant, unnecessary variable when the model accounts for changes in the cost of capital and effort. This result is consistent with hypothesis 2 .

Hypothesis 3, which addresses the interaction of SOC and standardized effort, is confirmed conditional on the level of exogenous uncertainty. As shown in Table 2 (grain operations), the coefficient of the interaction term is 0.494 and 
Table 3. Grain Farms: Mean Predicted and Observed Farm Success by Percentile Separated Ownership and Control Scores and Region

\begin{tabular}{|c|c|c|c|c|c|c|c|c|c|}
\hline \multirow[b]{2}{*}{ SOC Score } & \multicolumn{9}{|c|}{ ERS Region } \\
\hline & 1 & 2 & 3 & 4 & 5 & 6 & 7 & 8 & 9 \\
\hline \multicolumn{10}{|c|}{ Predicted Farm Success Score } \\
\hline Lower 50 percent & -0.06 & -0.14 & -0.06 & -0.03 & -0.10 & -0.13 & 0.12 & -0.03 & -0.03 \\
\hline Top 50 percent & 0.13 & 0.21 & 0.19 & 0.13 & 0.10 & 0.16 & 0.17 & 0.15 & 0.26 \\
\hline \multicolumn{10}{|l|}{ Return to Capital } \\
\hline Lower 50 percent & 0.03 & -0.01 & 0.04 & 0.04 & -0.01 & 0.01 & 0.00 & 0.02 & 0.05 \\
\hline Top 50 percent & 0.06 & 0.07 & 0.07 & 0.07 & 0.09 & 0.07 & 0.07 & 0.06 & 0.09 \\
\hline \multicolumn{10}{|c|}{ Return to Labor and Management (thousand dollars) } \\
\hline Lower 50 percent & 84.13 & 17.49 & 72.89 & 67.55 & 8.52 & 41.60 & 42.33 & 55.42 & 96.48 \\
\hline Top 50 percent & 178.92 & 218.34 & 168.23 & 140.08 & 210.66 & 201.57 & 329.26 & 125.97 & 228.98 \\
\hline \multicolumn{10}{|c|}{ Ownership Share (percent) } \\
\hline Lower 50 percent & 86.44 & 89.22 & 92.84 & 86.72 & 89.84 & 83.95 & 83.58 & 87.75 & 90.71 \\
\hline Top 50 percent & 39.40 & 57.55 & 51.33 & 44.43 & 62.91 & 48.81 & 55.45 & 56.97 & 51.98 \\
\hline \multicolumn{10}{|l|}{ Farm Count } \\
\hline Lower 50 percent & 13,039 & 3,669 & 2,022 & 4,712 & 1,325 & 3,665 & 3,652 & 928 & 1,852 \\
\hline Top 50 percent & 5,882 & 2,841 & 1,054 & 3,105 & 778 & 3,097 & 9,595 & 1,062 & 2,021 \\
\hline
\end{tabular}


Table 4. Livestock Farms: Mean Predicted and Observed Farm Success by Percentile Separated Ownership and Control Scores and Region

\begin{tabular}{|c|c|c|c|c|c|c|c|c|c|}
\hline \multirow[b]{2}{*}{ SOC Score } & \multicolumn{9}{|c|}{ ERS Region } \\
\hline & 1 & 2 & 3 & 4 & 5 & 6 & 7 & 8 & 9 \\
\hline \multicolumn{10}{|c|}{ Predicted Farm Success Score } \\
\hline Lower 50 percent & -0.19 & -0.27 & -0.21 & -0.20 & -0.24 & -0.22 & -0.23 & -0.34 & -0.21 \\
\hline Top 50 percent & 0.12 & 0.08 & 0.12 & 0.08 & 0.03 & 0.07 & 0.13 & 0.08 & 0.09 \\
\hline \multicolumn{10}{|l|}{ Return to Capital } \\
\hline Lower 50 percent & -0.01 & -0.04 & -0.02 & -0.02 & -0.02 & -0.01 & -0.03 & -0.03 & -0.02 \\
\hline Top 50 percent & 0.06 & 0.03 & 0.05 & 0.06 & 0.01 & 0.04 & 0.05 & 0.05 & 0.05 \\
\hline \multicolumn{10}{|c|}{ Return to Labor and Management (thousand dollars) } \\
\hline Lower 50 percent & 34.02 & 7.86 & -14.74 & -20.27 & -5.59 & -7.01 & 8.13 & -47.65 & -7.23 \\
\hline Top 50 percent & 207.88 & 205.85 & 235.36 & 179.85 & 22.92 & 84.36 & 258.05 & 89.74 & 136.80 \\
\hline \multicolumn{10}{|c|}{ Ownership Share (percent) } \\
\hline Lower 50 percent & 98.14 & 99.00 & 98.46 & 98.49 & 98.67 & 98.77 & 98.83 & 98.72 & 98.98 \\
\hline Top 50 percent & 31.94 & 48.42 & 43.79 & 38.33 & 44.66 & 50.17 & 41.19 & 50.61 & 52.69 \\
\hline \multicolumn{10}{|l|}{ Farm Count } \\
\hline Lower 50 percent & 4,971 & 3,980 & 1,179 & 3,828 & 5,132 & 5,418 & 3,366 & 1,079 & 988 \\
\hline Top 50 percent & 5,212 & 4,805 & 1,064 & 3,842 & 3,493 & 4,906 & 5,002 & 1,136 & 578 \\
\hline
\end{tabular}


is statistically significant. For grain farms, increasing SOC and effort leads to gains-likely from greater specialization of farm labor effort and greater farm success. Livestock farms, on the other hand, are found to not be significantly impacted by the interaction of labor effort and SOC.

The results of our empirical analysis support the validity of the theoretical framework described by Allen and Lueck and the posited relationships between agency cost, farm success, exogenous uncertainty, and enforceable agent effort. They further provide empirical support for the hypothesis that the cost of agency can limit the success of farms organized with SOC in general and grain farms in particular.

Though tests of the hypotheses support the framework described by Allen and Lueck, the observed and predicted farm success scores draw a starkly different picture of the future of farm organization given exogenous uncertainty. Tables 3 (grain operations) and 4 (livestock operations) present the mean values for success for the farms in the upper and lower 50th percentiles in degree of SOC by ERS region. The results point to a consistent overall relationship in the scores for the two percentiles. For example, in region 1 the mean predicted farm success score for the lower 50th percentile of SOC is -0.6 while the mean predicted farm success score for the upper 50 th percentile is 0.13 .

Because the predicted farm success scores are somewhat difficult to interpret due to their latent derivation, we also report the observed mean return to capital and return to labor and management for these groups by region in the tables. For example, for grain farms in region 1, we observe a difference between the percentiles in mean return to capital, which are 0.06 for the upper 50th and 0.03 for the lower 50th, and in mean returns to labor and management, which are $\$ 84,000$ for the lower 50th SOC percentile and $\$ 179,000$ for the upper 50th percentile.

Lastly, we report the primary operator's mean degree of ownership and the number of farms in the category by ERS region. In region 1, mean ownership for grain farmers is 86 percent for the lower 50th percentile of SOC scores and only 39 percent for the upper 50th percentile. The farm counts further indicate that a disproportionate number of farms in regions 7 (Fruitful Rim), 8 (Southern Seaboard), and 9 (Mississippi Portal) have relatively high degrees of SOC.

\section{Conclusions}

We contribute to the literature on farm organization and agency cost by empirically examining the effect of separating ownership and control of a farm on farmer effort and farm success using grain and livestock operations. We find that increasing farmer effort has a positive and unique direct effect on farm success for single-owner, partnership, and corporate farms. We also find that SOC is not an important indicator of farm success once we control for the cost of capital, effort, and specialization. As predicted, the interaction 
of SOC with mean farmer effort is significantly positive for farm success for grain farms but not for livestock operations. We therefore conclude that there may be a cost of agency associated with enforcing the level of optimal effort necessary for maximum farm success when there is SOC and exogenous uncertainty. When farms are able to enforce the optimal level of effort, greater farm success is expected.

However, our findings suggest that traditional agency-cost frameworks used to understand the evolution of farm organizations have failed in key respects. Though agency problems and exogenous uncertainty can explain the inability of some farms to achieve maximum success, SOC farms generally perform better overall. We do not observe a complete offsetting effect from misaligned interests.

Additional research is needed to predict and explain how and why farm organizational structures are evolving. Our results suggest that farms will continue to evolve to have greater separation between ownership and control but do not identify specific advantages of it (e.g., specialization, risk-sharing, asset-specific investment, horizon efficiencies), how farms overall will evolve (e.g., whether existing SOC farms will expand and whether farms under combined ownership and control will become more separated), the rate of evolution, or factors that could precipitate or slow the evolution. Future research should be directed toward the advantages of SOC and away from the agency cost-at least, the agency cost as an input of "labor effort" - as the primary driver of farm organization choices. Furthermore, future research should seek to understand why agency cost seems to be relatively unimportant, allowing SOC to prosper. Perhaps technological developments in monitoring instruments have reduced the cost and/or improved the effectiveness of monitoring. Or signaling and improved knowledge of the production function by principals may have enhanced their ability to bind agent effort using contracts at desired levels and avoid costs in observing agent effort. Until further studies are completed, we can only speculate.

Understanding the impact of agency relationships in farming improves our ability to predict the evolution of farm organizational structures and evolutionary pressures. This knowledge could allow us to anticipate changes in rural farm economies and improve their overall economic efficiency by reducing transaction costs. Quantifying the magnitude of incentive effects in farm organizations can inform farm producers and financial and legal advisors as they structure farm organizations to maintain efficiency and seek incentive schemes that can minimize costs and maximize benefits to farm workers and stakeholders.

\section{References}

Allen, D.W, and D. Lueck. 1992. "Contract Choice in Modern Agriculture: Cash Rent versus Cropshare." Journal of Law and Economics 35(2): 397-426.

- 1998. "The Nature of the Farm." Journal of Law and Economics 41(2): 343-386. 
Bahls, S.C. 1994. "Judicial Approaches to Resolving Dissension among Owners of the Family Farm.” Nebraska Law Review 73(1): 14-47.

Basmann, R.L. 1960. "On Finite Sample Distributions of Generalized Classical Linear Identifiability Test Statistics." Journal of the American Statistical Association 55(292): 650-659.

Berle, A.A., and G.C. Means. 1932. The Modern Corporation and Private Property. New York, NY: MacMillan.

Boland, M., and T.L. Marsh. 2006. "Input Quality in the Sugar Beet Industry." Journal of Agricultural and Resource Economics 31(1): 114-128.

Cheung, S.N.S. 1969. "Transaction Costs, Risk Aversion, and the Choice of Contractual Arrangements." Journal of Law and Economics 12(1): 23-42.

Cunningham, D.L. 2009. "Guide for Prospective Contract Broiler Producers." Athens, GA: University of Georgia Extension. http://extension.uga.edu/publications/detail.cfm? number=B1167 (accessed December 10, 2016).

Dasgupta, S., T.O. Knight, and H.A. Love. 1999. "Evolution of Agricultural Land Leasing Models: A Survey of the Literature." Review of Agricultural Economics 21(1): 148-176.

Eswaran, M., and A. Kotwal. 1985. "A Theory of Contractual Structure in Agriculture." American Economic Review 75(3): 352-367.

Fama, E.F., and M.C. Jensen. 1983a. “Separation of Ownership and Control." Journal of Law and Economics 26(2): 301-325.

_. 1983b. "Agency Problems and Residual Claims." Journal of Law and Economics 26(2): 327-349.

Gorton, M., and S. Davidova. 2004. "Farm Productivity and Efficiency in the CEE Applicant Countries: A Synthesis of Results." Agricultural Economics 30(1): 1-16.

Grossman, S.J., and O.D. Hart. 1983. "An Analysis of the Principal-Agent Problem." Econometrica 51(1): 7-45.

Hallagan, W. 1978. "Self-selection by Contractual Choice and the Theory of Sharecropping." Bell Journal of Economics 9(Autumn): 344-354.

Hoppe, R., J. Johnson, J.E. Perry, P. Korb, J.E. Sommer, J.T. Ryan, R.C. Green, R. Durst, and J. Monke. 2001. "Structural and Financial Characteristics of U.S. Farms: 2001 Family Farm Report." Economic Research Service, USDA, Washington, DC.

Kaiser, H.F. 1960. "The Application of Electronic Computers to Factor Analysis." Educational and Psychological Measurement 20: 141-151.

Key, N., and W.D. McBride. 2008. "Do Production Contracts Raise Farm Productivity? An Instrumental Variables Approach." Agricultural and Resource Economics Review 37(2): 176-187.

Jensen, M.C., and W.H. Meckling. 1976. "Theory of the Firm: Managerial Behavior, Agency Costs, and Ownership Structure." Journal of Financial Economics 3(4): 305-360.

Latruffe, L., K. Balcombe, S. Davidova, and K. Zawalinska. 2005. "Technical and Scale Efficiency of Crop and Livestock Farms in Poland: Does Specialization Matter?" Agricultural Economics 32(3): 281-296.

MacDonald, J.M., J. Perry, M. Ahearn, D. Banker, W. Chambers, C. Dimitri, N. Key, K.E. Nelson, and L.W. Southard. 2004. "Contracts, Markets, and Prices: Organizing the Production and Use of Agricultural Commodities." Agricultural Economic Report 837, Economic Research Service, USDA, Washington, DC.

Marshall, A. 1920. Principles of Economics: An Introductory Volume. London, UK: Macmillan.

Mench, J.A., H.S. James Jr., E.A. Pajor, and P.B. Thompson. 2008. "The Welfare of Animals in Concentrated Animal Feeding Operations." Technical Report, Pew Commission on Industrial Farm Animal Production and Johns Hopkins Bloomberg School of Public Health, Baltimore, MD.

Mishra, A.K., H.S. El-Osta, and J.D. Johnson. 1999. "Factors Contributing to Earnings Success of Cash Grain Farms." Journal of Agricultural and Applied Economics 31(3): 623-637. 
National Agricultural Statistics Service. 2009. "2007 Census of Agriculture, Vol. 1: Part 51, Chapter 1, AC-07-A-51, United States Summary and State Data." NASS, U.S. Department of Agriculture, Washington, DC.

Otsuka, K., and Y. Hayami. 1988. "Theories of Share Tenancy: A Critical Survey." Economic Development and Cultural Change 37(1): 31-68.

Scholes, M.L., M. Wright, P. Westhead, A. Burrows, and H. Bruining. 2007. "Information Sharing, Price Negotiation, and Management Buy-outs of Private Family Owned Firms." Small Business Economics 29(3): 329-349.

Stiglitz, J.E. 1974. "Incentives and Risk Sharing in Sharecropping." Review of Economic Studies 41(2): 219-255.

U.S. Department of Agriculture. 2005-2010. Agricultural Resource Management Survey. Economic Research Service and National Agricultural Statistics Service, USDA, Washington DC. 